\title{
COMENTÁRIO A "O ENSINO E A PESQUISA EM HiSTóRIA ANTIGA NO BRASIL: REFLEXÕES A PARTIR DOS DADOS DA PLATAFORMA LATTES"
}

Rafael da Costa Campos ${ }^{1}$

As proposições do artigo de Santos, Kolv e Nazário nos confirmam, de imediato, a expansão do interesse e o crescimento da produtividade científica na área de Antiguidade no Brasil. Não é demais relembrar aos leitores especialmente aqueles pouco familiarizados com esta temática - que em pouco mais de três décadas pudemos sair da iniciativa quase que individual de nossos primeiros intelectuais devotados aos estudos sobre História Antiga e Medieval, para um outro patamar, o de uma prolífica produção que emerge em uma proporção comparativa ao que se desenvolve em outras áreas da historiografia brasileira.

Contudo, gostaria de aproveitar o espaço para abordar os desafios que nós, pesquisadores e docentes dedicados à área, continuamos enfrentando para a produção e ensino de História Antiga no Brasil. De início, é importante salientar que no âmbito das universidades e cursos de graduação e pós-graduação em História, ainda há muito o que disputar - e essa palavra é a que julgo mais adequada - no que tange à ampliação e popularização dos estudos sobre Antiguidade. Os projetos pedagógicos de cursos de graduação em História não consistem apenas de uma conjugação de reflexões acerca do que pode ser compatível com os horizontes de expectativas do conhecimento histórico. Esses documentos, pedra angular da organização do ensino de qualquer graduação no interior dos institutos e faculdades dentro das universidades, são configurados mediante demandas de ordem epistemológica, mas, sobretudo, sob pressões político-institucionais de uma gama variada de agentes, dentro e fora das próprias universidades.

Dito de outro modo, os projetos de desenvolvimento institucionais universitários condicionam quais são as expectativas de promoção da articulação ensino-pesquisa-extensão de uma instituição superior de ensino para a

\footnotetext{
${ }^{1}$ Doutor em História Social pela Universidade de São Paulo. Professor Adjunto da Universidade Federal do Pampa - Campus de Jaguarão. E-mail: rafaelcampos@unipampa.edu.br.
} 
comunidade externa ao redor. Diametralmente, dependendo da instituição, de sua posição enquanto centro de excelência ou proximidade dos grandes centros brasileiros, essas expectativas naturalmente condicionam os cursos de graduação e pós-graduação, e finalmente quais são os objetivos dos projetos pedagógicos dos cursos, seja em licenciatura ou bacharelado. Não nos deixemos enganar: as pressões exercidas no escopo dessas expectativas são, a meu ver e cada vez mais, políticas e atreladas aos interesses do capital.

Consequentemente, essas expectativas ditarão o quantitativo de vagas para a realização de concursos públicos para docentes efetivos em departamentos ou comissões de curso de graduação. Igualmente, a quantidade de docentes efetivados para a implantação de uma graduação condicionará - fatalmente - a organização curricular dos projetos pedagógicos de curso - e a possível distribuição dos encargos docentes em diferentes áreas do saber. Sabemos que no Brasil, com poucas exceções, as instituições superiores de ensino, principalmente as do setor público estadual e federal, contam com um quantitativo docente aquém da quantidade de subdivisões nas diferentes grandes áreas do saber.

Especificamente, e para melhor ilustrar minha problematização, pensemos em uma graduação em História. Na maior parte das universidades brasileiras, raramente contabilizamos um docente efetivo com dedicação exclusiva somente à sua especialidade de pesquisa - constituída pelos anos de pesquisa em mestrado, doutorado e pós-doutorado. Como exemplo, desconheço um docente dentro de uma universidade brasileira que goza do "privilégio" de se dedicar exclusivamente a ministrar disciplinas relacionadas à organização sociopolítica do Principado Romano. Esse docente pode considerar-se felizardo caso consiga ministrar essencialmente disciplinas dentro do escopo da "História Antiga”, convenção que, de acordo com Guarinello (2013, p. 14), ainda consiste no emprego de uma linha do tempo com histórias sucessivas que não faz sentido (Guarinello, 2013). Assim, é mais comum que um docente ministre não só encargos de ensino ainda convencionados em uma perspectiva praticamente hegeliana de História, presentes nos projetos pedagógicos de cursos de graduação, mas que se veja condicionado a ministrar disciplinas que não condizem com sua área de especialização.

Obviamente, os efeitos dessas condições estruturantes são perceptíveis nos componentes curriculares ensinados nos cursos de História. É bastante 
provável que o arcabouço de conhecimento acumulado de um docente responsável por História Moderna, mas especialista em História Antiga, seja menor do que o de um pós-graduado com pesquisas inscritas na primeira grande área mencionada, e vice-versa. Isso impede que haja qualidade em uma aula ministrada nessas condições? Creio que não necessariamente. Contudo, esse docente - via de regra - terá de realizar um trabalho hercúleo: o de conseguir acompanhar a produção do conhecimento e se atualizar nas diversas áreas pelas quais ele tem de se responsabilizar no ensino de graduação. Admito que sou bastante cético quanto às possibilidades de sucesso nessa empreitada, e raramente observo tal polivalência entre meus pares.

Deste modo, podemos sintetizar, para começo de conversa, alguns problemas estruturantes para a pesquisa e ensino de História e a pesquisa e o ensino de História Antiga, na gênese de sua produção tradicional, que é a universidade: vicissitudes originárias dos projetos políticos e institucionais das universidades brasileiras; a estruturação da carreira docente dentro das mesmas; a paralisia epistemológica na construção dos projetos pedagógicos de curso de graduação em História - cujos condicionantes essenciais são impostos pelas leis e diretrizes básicas do Ministério da Educação - e o perfil de professor universitário nas instituições superiores de ensino brasileiras.

Esses problemas não incidem somente sobre os docentes pesquisadores da Antiguidade. Em verdade, a querela entre a hiperespecialização e o generalismo acomete todos os docentes distribuídos nas mais variadas áreas do conhecimento histórico nos cursos de graduação. Alguns desses cursos contam com pouco mais de dez docentes, que destrincham as matrizes curriculares, sendo relativamente comum um professor especialista em Antiguidade ministrar "História Antiga", "História Medieval", ou mesmo "Teorias da História" ou "Metodologia Científica", geralmente com encargos de doze a dezesseis horas de sala de aula por semana. Com esse cenário, já se torna bastante complicado desenvolver pesquisas de fôlego na área de especialização em Antiguidade, quiçá em outras.

Outro problema bastante presente - e que considero tão grave quanto o anterior - diz respeito ao espaço que a disciplina "História Antiga" possui nos cursos de graduação em História. É salutar relembrar os efeitos do avanço da pesquisa nesta área nos últimos 30 anos, e que a profusão de novos profissionais 
especializados tendo assumido a responsabilidade pela disciplina é um fenômeno notável e significativo. Isso se deu, a meu ver, pelo fato de as gerações de docentes universitários das décadas de 1980 e 1990 terem ajudado na formação de doutores, que durante as duas últimas décadas têm saído dos programas de pósgraduação e se efetivado em universidades de grandes centros, mas também em universidades de centros menores e universidades novas no interior do Brasil. A reboque, há a promoção de eventos de área, difusão das pesquisas em periódicos, livros organizados, dentre outros.

Contudo, isso não atenuou a perene disputa no interior dos departamentos para pleitear não só que o docente responsável por "História Antiga" não receba também "História Medieval" ou "História Moderna" por tabela - como se tudo fizesse parte de um grande contexto generalista de "História da Europa" ou "períodos históricos pré-industriais", mas principalmente para que a Antiguidade não seja tão restringida dentro da matriz curricular obrigatória ou mesmo extirpada como um componente optativo, ou que alguns cursos de graduação tenham interesse em dispor - especialmente nas universidades públicas - de um código de vaga para concurso de docente efetivo especialista nessa área, uma necessidade por vezes questionada dentro dos próprios departamentos por pares de outras áreas do conhecimento histórico.

Pois bem, esse conjunto de condições assoma-se de modo a preestabelecer as vertentes da História Antiga ensinada e pesquisada no ambiente acadêmico brasileiro. Mais ainda, direciona a formação dos docentes e pesquisadores que tem se graduado e especializado nos programas lato e strictu senso nacionais. As considerações expostas por Santos et al. evidenciam muito bem que a preponderância pela chamada "tradição clássica" nos currículos dos docentes e discentes pesquisadores é um natural enviesamento que julgo não advir apenas das escolhas pessoais no que tange aos campos de interesse dentro da Antiguidade, mas por relações de interdependência acadêmica e mecanismos de pressão institucionais das mais diversas ordens. Em outras palavras, se os estudos sobre Antiguidade naturalmente remam contra a maré dentro da academia brasileira, segmentos como Antiguidade Oriental ou estudos sobre sociedades para além do recorte espaço-temporal do que pode se convencionar como Mediterrâneo Antigo são ainda mais raros e sufocados dentro dessa engrenagem. 
Contudo, se esse panorama pode parecer pouco satisfatório, creio que na verdade seja um mal menor. A partir do apresentado pelos colegas no artigo, julgo que o grande desafio para nós, pesquisadores dessa área, seja o de popularizar a Antiguidade para bem além dos fóruns específicos de discussão, essencialmente circunscritos aos grupos de trabalho, centros de pesquisa, em suma, o ambiente da universidade. Por estarmos geograficamente e historicamente distantes daquilo que trivialmente se concebe como os nascedouros das sociedades que compuseram o recorte tradicionalmente dado para a História Antiga, fatalmente acabamos por reiterar o distanciamento, a excentricidade e o elitismo que transparece aos olhos do senso comum quando se pensa sobre o Mundo Antigo.

Definitivamente, o olhar de um leigo não é obrigado e tecer conexões argumentativas que justifiquem as possibilidades de se pensar e pesquisar a Antiguidade nos lados de cá do Oceano Atlântico. Controvérsias à parte, a despeito da reiteração de mitologias políticas gestadas especialmente entre os séculos XVIII e XIX, que versam a respeito de matrizes étnicas e culturais oriundas de gregos, romanos, gauleses, povos germânicos ou célticos que os europeus reiteram até os dias de hoje para si, é muito mais fácil para essas sociedades verem seus sujeitos atravessarem a rua e travarem contato direto sobretudo com a cultura material - dessas antigas sociedades. Do mesmo modo, essa relação mais direta manifesta-se nos meios de comunicação de massa: é relativamente comum canais abertos de televisão da comunidade europeia apresentarem constantemente documentários, ficções televisivas e cinematográficas, ou semanários de história de apelo popular que reiterem, mesmo com as devidas ressalvas sobre os anacronismos possíveis, o fascínio sobre e a influência dessas sociedades sobre a Europa contemporânea.

Não contamos com esses "aportes" facilitadores para debater a Antiguidade por cá. E isso não necessariamente é algo incontornável. As possibilidades de interconexões com esse passado histórico são debatidas em estudos sobre a recepção das tradições do Mundo Antigo durante a Modernidade e a Contemporaneidade. Conexões possíveis estão presentes na tradição artística e literária portuguesa, e que também se fez presente em nossos matizes socioculturais. Apropriações de diversas naturezas, muitas vezes de uma maneira naïf, são perceptíveis na arquitetura colonial e inclusive contemporânea. 
Enunciei brevemente algumas possibilidades, sem querer me delongar a respeito. Não é o que julgo me caber nessa réplica. ${ }^{2}$ Em verdade, vejo a necessidade de buscarmos uma maior interlocução com o Ensino Básico. Faz-se necessário que produzamos conteúdos acessíveis que permitam uma maior popularização da História Antiga para educadores e estudantes nessa etapa de formação. Um exemplo dessa iniciativa - e do exercício de transposição didática - tão premente para ampliarmos esse horizonte de discussões materializou-se nas obras produzidas por Carlos Augusto Machado (2009) e Marcelo Rede (2009), 3 e que visaram esse público. Iniciativas como essas devem ser buscadas incessantemente, a despeito de todos os pormenores que envolvem os interesses de um mercado editorial mais amplo, especialmente aquele voltado para a produção de livros didáticos para esse âmbito.

Igualmente, é necessário ampliarmos as discussões acerca do ensino de História Antiga. Podemos elencar vários artigos que apresentam problematizações a esse respeito, mas - ainda sem dados empíricos de amostragem mais ampla - pouco do debate, seja sobre a produção científica específica de pesquisadores brasileiros a respeito da Antiguidade, ou mesmo sobre questões que versam a respeito de seu ensino, aparecem nas coleções didáticas.

Quais são as razões desse fato e quais são os possíveis encaminhamentos? Seria demasiada pretensão oferecer um diagnóstico definitivo e uma solução geral.

Me limito a apresentar constatações sintomáticas sobre o primeiro aspecto: alguns dos autores de coleções didáticas buscam - quando muito algumas obras clássicas de pesquisadores estrangeiros, geralmente em língua portuguesa e bastante datadas. Não raramente as referências bibliográficas sequer mencionam obras específicas da área de Antiguidade. Algumas obras gerais de pesquisadores brasileiros são referenciadas na bibliografia, mas não são citadas no corpo do texto. Mais ainda, por vezes há uma semelhança um tanto estranha de conteúdo de coleções diferentes dentro da mesma editora, com raríssimas atualizações substanciais de texto entre uma edição e outra, mesmo entre organizadores diferentes. E por fim, quando não se insiste em uma

\footnotetext{
${ }^{2}$ Possibilidades a respeito são apresentadas na obra de Chevitarese et al. (2008).

3 Obras da coleção Que História é essa?, da editora Saraiva.
} 
perspectiva cronológica e convencional que sintetiza em meia dúzia de páginas alguns milênios, como na síntese de "temas essenciais da Antiguidade", exemplificados em possíveis títulos como "Pirâmides, faraós e culto religioso no Antigo Egito", "Democracia Ateniense", "Reforma Agrária em Roma”, "Ascensão do Cristianismo" e "Invasões bárbaras e fim do Império Romano", opta-se por paralelismos temáticos mais pungentes à contemporaneidade sem uma discussão mais aprofundada, perigosamente beirando ao anacronismo e a superficialidade.

Quanto ao segundo aspecto, faço simultaneamente um mea culpa e uma provocação: tanto o ensino de História e o ensino de História Antiga devem ocupar um lugar de maior destaque nos debates acadêmicos, eventos da área e, consequentemente pesquisa e produção científica. Observo uma (natural) tendência de imersão nas especificidades das pesquisas consolidadas de docentes e pesquisadores acerca de seus temas ad nauseam que nem sempre transcendem os horizontes das especialidades, de suas fontes e de suas metodologias. Naturalmente isso não é exclusividade dos pesquisadores de nossa área, aqui ou no exterior. Igualmente, não se trata de desdém pelo assunto. Afinal, as demandas institucionais e demais pressões inerentes ao universo acadêmico cerceiam o desenvolvimento satisfatório de nossas especialidades. Assim, retomo o início desta réplica e todos os argumentos de ordem normalizadora que impõem barreiras e - não raramente - promovem neuroses nesse ambiente: uma coleção de sintomas da hiperespecialização e das necessidades abusivas de produtivismo que nos atormentam e não raramente impedem a produção de reflexões de maior escopo ou de melhor maturação. Portanto, da provocação passemos para o desafio: o de inserir os debates sobre ensino de História Antiga nos fóruns de discussão e produção científica de nossa área, de modo que esse acúmulo possa interagir com as reflexões sobre a prática do docente pesquisador, bem como o conhecimento produzido também no ambiente da docência escolar. A meu ver, esse é um dos caminhos de uma longuíssima trajetória de ampliação da pesquisa, ensino e popularização do conhecimento por Antiguidade no Brasil, que não pode e não deve se restringir exclusivamente ao ambiente universitário, sob o risco de óbito por inanição. 


\section{Referências Bibliográficas}

Chevitarese, A. L.; Cornelli, G. ; Silva, M. A. O. A Tradição Clássica e o Brasil. Brasília: Archai/Fortium, 2008.

Guarinello, Norberto Luiz. História Antiga. São Paulo: Contexto, 2013.

Machado, Carlos Augusto R. Roma e seu Império. São Paulo: Saraiva, 2009.

Rede, Marcelo. Mesopotâmia. São Paulo: Saraiva, 2009. 